\title{
Engineering Infectious cDNAs of Coronavirus as Bacterial Artificial Chromosomes
}

\section{Fernando Almazán, Silvia Márquez-Jurado, Aitor Nogales, and Luis Enjuanes}

\begin{abstract}
The large size of the coronavirus $(\mathrm{CoV})$ genome (around $30 \mathrm{~kb}$ ) and the instability in bacteria of plasmids carrying $\mathrm{CoV}$ replicase sequences represent serious restrictions for the development of $\mathrm{CoV}$ infectious clones using reverse genetic systems similar to those used for smaller positive sense RNA viruses. To overcome these problems, several approaches have been established in the last 13 years. Here we describe the engineering of $\mathrm{CoV}$ full-length cDNA clones as bacterial artificial chromosomes (BACs), using the Middle East respiratory syndrome $\mathrm{CoV}$ (MERS-CoV) as a model.
\end{abstract}

Key words Coronavirus, MERS, Reverse genetics, Infectious clones, Bacterial artificial chromosomes

1 Introduction

Coronaviruses $(\mathrm{CoV})$ are enveloped, single-stranded, positivesense RNA viruses relevant in animal and human health $[1,2]$. Historically, $\mathrm{CoV}$ infection in humans has been associated with mild upper respiratory tract diseases [1]. However, the identification of the severe acute respiratory syndrome $\mathrm{CoV}$ (SARS-CoV) in 2003 [3] and the recently emerged (April 2012) Middle East respiratory syndrome $\mathrm{CoV}$ (MERS-CoV) [4], which has been associated with acute pneumonia, redefined historic perceptions and potentiated the relevance of CoVs as important human pathogens. In this sense, the development of $\mathrm{CoV}$ infectious clones provides a valuable molecular tool to study fundamental viral processes, to develop genetically defined vaccines, and to test antiviral drugs. However, the generation of $\mathrm{CoV}$ infectious clones has been hampered for a long time due to the huge size of the CoV genome (around $30 \mathrm{~kb}$ ) and the toxicity of some $\mathrm{CoV}$ replicase gene sequences during its propagation in bacteria. Recently, these problems were overcome using nontraditional approaches based 


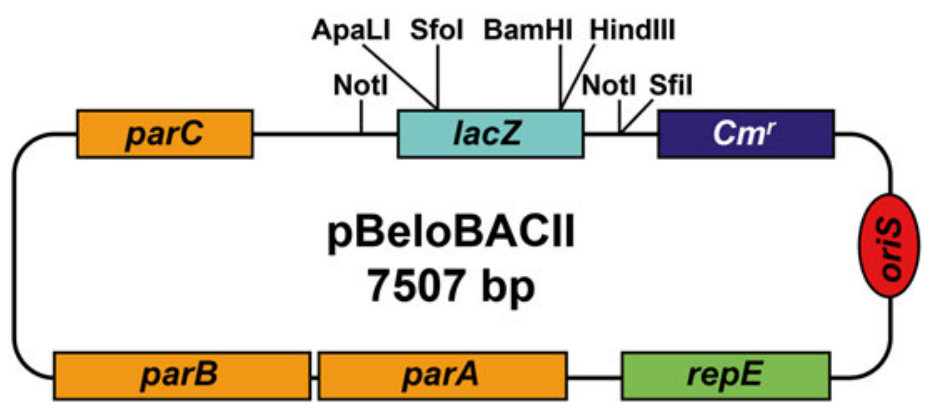

Fig. 1 Schematic of plasmid pBeloBAC11. The regulatory genes parA, parB, parC, and $r e p E$, the F-factor replication origin (OriS), the chloramphenicol resistance gene $(\mathrm{Cmr})$, the lacZ gene, and the restriction sites that can be used to clone foreign DNAs are indicated

on the use of bacterial artificial chromosomes (BACs) [5], in vitro ligation of cDNA fragments [6], and vaccinia virus as a vector for the propagation of $\mathrm{CoV}$ full-length cDNAs $[7,8]$.

In this chapter we describe the protocol to assemble CoV fulllength cDNAs in BACs using the MERS-CoV EMC12 strain [9] as an example. In this system, the full-length cDNA copy of the viral genome is assembled in the BAC plasmid pBeloBAC11 [10] (Fig. 1), a low-copy-number plasmid based on the Escherichia coli (E. coli) F-factor [11] that presents a strictly controlled replication leading to one or two plasmid copies per cell. This plasmid minimizes the instability problem of several $\mathrm{CoV}$ sequences when amplified in high-copy-number plasmids, allows the stable maintenance of large DNA fragments in bacteria [11], and its manipulation is similar to that of conventional plasmids. The cDNA of the $\mathrm{CoV}$ genome is assembled in the BAC under the control of the cytomegalovirus (CMV) immediate-early promoter and it is flanked at the 3 '-end by a 25 -bp synthetic poly(A) followed by the sequences of the hepatitis delta virus (HDV) ribozyme and the bovine growth hormone $(\mathrm{BGH})$ termination and polyadenylation signals to produce synthetic RNAs bearing authentic 5'- and $3^{\prime}$-ends of the viral genome. This DNA-launched system couples expression of the viral RNA in the nucleus from the CMV promoter [12] with a second amplification step in the cytoplasm driven by the viral polymerase, allowing the recovery of infectious virus from the cDNA clone without the need for in vitro ligation and transcription steps. Although some splicing events could occur during the nuclear expression of the viral genome, the efficiency of this phenomenon is very low and does not affect the recovery of infectious virus [5].

The BAC approach, originally applied to the transmissible gastroenteritis coronavirus (TGEV) [5], has been successfully used to engineer the infectious clones of the feline infectious peritonitis virus (FIPV) [13] and the human CoVs (HCoVs): HCoV-OC43 [14], 
SARS-CoV [15], and MERS-CoV [16], and it is potentially applicable to the cloning of other $\mathrm{CoV}$ cDNAs, other viral genomes, and large-size RNAs of biological relevance.

\section{Materials}

\subsection{Assembly and Manipulation of BAC Clones}

2.1.1 Plasmids and Bacterial Strains

2.1.2 Culture Media for E. coli
To reach optimal results, all solutions should be prepared using pure Milli-Q grade water (resistivity of $18.2 \mathrm{M} \Omega / \mathrm{cm}$ at $25^{\circ} \mathrm{C}$ ) and analytical grade reagents.

1. Plasmid pBeloBAC11 [10]. This plasmid contains genes parA, $\operatorname{par} B$, and $\operatorname{par} C$ derived from the $E$. coli F-factor to ensure the accurate partitioning of plasmids to daughter cells, avoiding the possibility of coexistence of multiple BACs in a single cell. In addition, this plasmid carries gene repE and the element oriS involved in initiation and orientation of DNA replication, the chloramphenicol resistance gene $(\mathrm{Cmr})$, the lac $Z$ gene to allow color-based identification of recombinants by $\alpha$-complementation, and the restriction sites ApaLI, SfoI, BamHI, HindIII, and SfiI to clone large DNA fragments (Fig. 1).

2. pBeloBAC 1 $1^{\text {-StuI }}$, a pBeloBAC without the StuI restriction site.

3. E. coli $\mathrm{DH} 10 \mathrm{~B}$ strain $\left[\mathrm{F}^{-}\right.$mcrA $\Delta$ (mrr-hsdRMS-mcrBC) Ø80dlacZ $\Delta \mathrm{M} 15 \quad \Delta$ lacX74 deoR recAl endAl araDl39 (ara, leu)7697 galU galK $\lambda^{-}$rpsL nupG] (see Note 1).

4. DH10B electrocompetent cells. These bacterial cells could be purchased or prepared following the procedure described in Subheading 3.2.3.

1. LB medium: $1 \%(\mathrm{w} / \mathrm{v})$ tryptone, $0.5 \%(\mathrm{w} / \mathrm{v})$ yeast extract, $1 \%(\mathrm{w} / \mathrm{v}) \mathrm{NaCl}$. Adjust the $\mathrm{pH}$ to 7.0 with $5 \mathrm{~N} \mathrm{NaOH}$. Sterilize by autoclaving on liquid cycle.

2. LB agar plates: LB medium containing $15 \mathrm{~g} / 1$ of Bacto Agar. Prepare LB medium and just before autoclaving add $15 \mathrm{~g} / \mathrm{l}$ of Bacto Agar. Sterilize by autoclaving on liquid cycle and dispense in 90-mm petri plates.

3. LB agar plates containing $12.5 \mu \mathrm{g} / \mathrm{ml}$ chloramphenicol. After autoclaving the LB agar medium, allow the medium to cool to $45{ }^{\circ} \mathrm{C}$, add the chloramphenicol to a final concentration of $12.5 \mu \mathrm{g} / \mathrm{ml}$ from a stock solution of $34 \mathrm{mg} / \mathrm{ml}$, and dispense in $90-\mathrm{mm}$ petri plates.

4. SOB medium: $2 \%(\mathrm{w} / \mathrm{v})$ tryptone, $0.5 \%(\mathrm{w} / \mathrm{v})$ yeast extract, $0.05 \%(\mathrm{w} / \mathrm{v}) \mathrm{NaCl}, 2.5 \mathrm{mM} \mathrm{KCl}$. Adjust the $\mathrm{pH}$ to 7.0 with $5 \mathrm{~N} \mathrm{NaOH}$ and sterilize by autoclaving on liquid cycle (see Note 2). 
2.1.3 Enzymes and Buffers

2.1.4 Special Buffers and Solutions

\subsubsection{Reagents}

\subsubsection{Special Equipment}

\subsection{Rescue} of Recombinant Viruses

\subsubsection{Cells}

2.2.2 Cell Culture Medium, Solutions and Reagents
5. SOC medium: SOB medium containing $10 \mathrm{mM} \mathrm{MgCl}_{2}$, $10 \mathrm{mM} \mathrm{MgSO}_{4}, 20 \mathrm{mM}$ glucose. After autoclaving the SOB medium, cool to $45{ }^{\circ} \mathrm{C}$ and add the $\mathrm{MgCl}_{2}, \mathrm{MgSO}_{4}$ and glucose from filter sterilized $1 \mathrm{M}$ stock solutions.

1. Restriction endonucleases.

2. Shrimp alkaline phosphatase.

3. T4 DNA ligase.

4. Taq DNA polymerase.

5. High-fidelity thermostable DNA polymerase.

6. Reverse transcriptase.

7. dNTPs.

8. Enzyme reaction buffers. Use the buffer supplied with the enzyme by the manufacturer.

1. LB freezing buffer: $40 \%(\mathrm{v} / \mathrm{v})$ glycerol in LB medium. Sterilize by passing it through a $0.45-\mu \mathrm{m}$ disposable filter.

2. Chloramphenicol stock $(34 \mathrm{mg} / \mathrm{ml})$. Dissolve solid chloramphenicol in ethanol to a final concentration of $34 \mathrm{mg} / \mathrm{ml}$ and store the solution in a light-tight container at $-20{ }^{\circ} \mathrm{C}$. This solution does not have to be sterilized.

3 . Ice-cold $10 \%$ glycerol in sterile water.

1. Qiagen QIAprep Miniprep Kit.

2. Qiagen Large-Construct Kit.

3. Qiagen QIAEX II Kit.

1. Equipment for electroporation.

2. Cuvettes fitted with electrodes spaced $0.2 \mathrm{~cm}$.

1. Baby hamster kidney cells (BHK-21).

2. Human liver-derived Huh-7 cells (see Note 3).

1. Cell growth medium: Dulbecco's Modified Eagle Medium (DMEM) supplemented with $1 \%$ nonessential amino acids, gentamicin $(50 \mathrm{mg} / \mathrm{ml})$, and $10 \%$ fetal calf serum (FCS).

2. Opti-MEM I Reduced Serum Medium.

3. Trypsin-EDTA solution: $0.25 \%(\mathrm{w} / \mathrm{v})$ trypsin, $0.02 \%(\mathrm{w} / \mathrm{v})$ EDTA.

4. Lipofectamine 2000. 


\section{Methods}

\subsection{Assembly of Full-Length CoV cDNAs in BACs}

\subsubsection{Selection of Restriction}

Endonuclease Sites in the Viral Genome
The basic strategy for the generation of $\mathrm{CoV}$ infectious clones using BACs is described for the MERS-CoV EMC12 strain (GenBank accession number JX869059) [9] as a model (Fig. 2).

1. The first step for the assembly of the full-length cDNA clone is the selection of appropriate restriction endonuclease sites in the viral genome. These restriction sites must be absent in the BAC plasmid (see Note 4 ). In the case of MERS-CoV, the restriction sites BamHI (genomic position 806), StuI (genomic positions 7,620 and 9,072), SwaI (genomic position 20,898), and PacI (genomic position 25,836) were selected to assemble the infectious clone (Fig. 2).
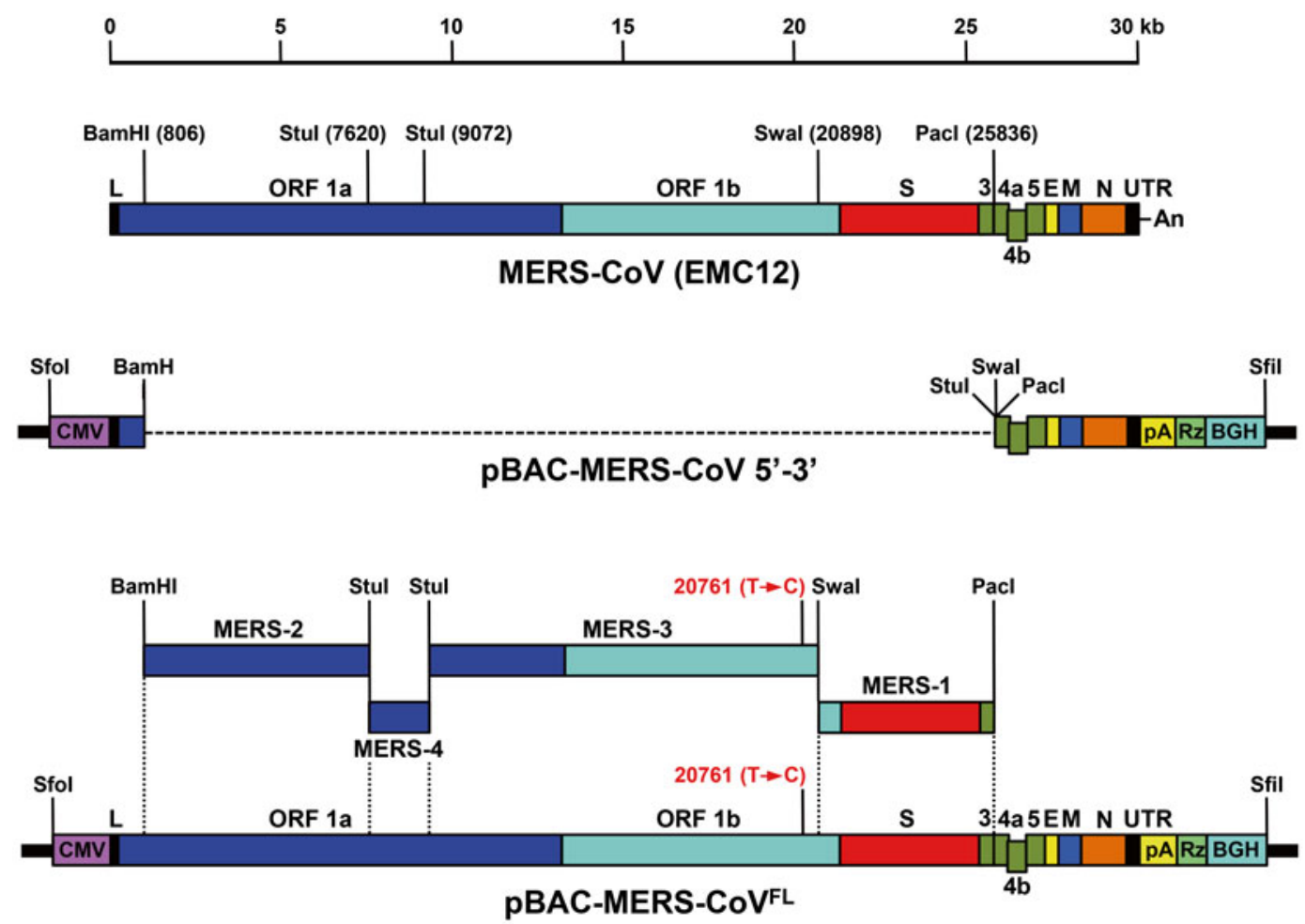

Fig. 2 Strategy to assemble a MERS-CoV infectious cDNA clone as a BAC. After selection of appropriate restriction sites in the genome of the MERS-CoV EMC12 strain (top of the figure), the intermediate plasmid pBACMERS-CoV 5'-3' was generated and used as the backbone to assemble the full-length cDNA clone (pBAC-MERS-CoVFL) by sequential cloning of four overlapping cDNA fragments (MERS-1 to MERS-4) covering the entire viral genome. The full-length clone is assembled in BAC under the control of the CMV promoter and it is flanked at the $3^{\prime}$-end by a 25 -bp poly (A) tail (pA) followed by the HDV ribozyme (Rz) and the BGH termination and polyadenylation sequences (BGH). The viral genes (ORF 1a, ORF 1b, S, 3, 4a, 4b, 5, E, M, and N), relevant restriction sites (genomic positions in brackets) and the genetic marker ( $\mathrm{T}$ to $\mathrm{C}$ ) introduced at position 20,761 to abrogate the Swal restriction site at position 20,760 are indicated. $L$ leader sequence, UTR untranslated region. Figure adapted from ref. [16] 


\subsubsection{Construction} of an Intermediate $B A C$ Plasmid as the Backbone to Assemble the FullLength cDNA Clone
2. In case that no adequate restriction sites were available in the viral genome, new restriction sites, appropriately spaced in the viral genome, could be generated by the introduction of silent mutations. In addition, natural restriction sites could be eliminated following the same approach to facilitate the assembly of the infectious clone (see Note $\mathbf{5}$ ).

The assembly of the infectious clone in a BAC is facilitated by the construction of an intermediate BAC plasmid containing the 5 '-end of the genome (until the first restriction site selected) under the control of the CMV promoter, a multicloning site containing the restriction sites selected in the first step, and the 3 '-end of the genome (from the last restriction site selected to the end of the genome) followed by a 25-nt poly(A) tail, the HDV ribozyme, and the $\mathrm{BGH}$ termination and polyadenylation sequences. All these elements have to be precisely assembled to produce synthetic RNAs bearing authentic 5'- and 3 '-ends of the viral genome. A detailed protocol for the generation of the MERS-CoV intermediate plasmid, pBAC-MERS-CoV 5'-3', is described next (Fig. 2).

1. Generate by chemical synthesis a DNA fragment containing the CMV promoter [12] precisely fused to the first $811 \mathrm{nt}$ of the viral genome (from the first nucleotide to the restriction site BamHI), flanked at the $5^{\prime}$ - and $3^{\prime}$-ends by restriction sites SfoI and BamHI, respectively. Alternatively, this DNA fragment could be generated by PCR using two overlapping PCR fragments as template ( see Notes 6 and 7). One of these fragments should contain the CMV promoter flanked at the 5 '-end by the restriction site SfoI and at the $3^{\prime}$-end by the 20 first nucleotides of the genome as overlapping sequence. The second overlapping PCR fragment should expand from the first nucleotide to the restriction site BamHI.

2. The generated DNA fragment is digested with SfoI and BamHI, and cloned into pBeloBACl1 ${ }^{\text {-Stul }}$ digested with the same restriction enzymes to generate the plasmid pBACMERS-CoV 5'.

3. Generate a second DNA fragment, containing the last 4,272 nt of the viral genome (from the restriction site PacI at genomic position 25,836 to the end of the genome) precisely joined to a 25-nt $\operatorname{poly}(\mathrm{A})$ tail, the HDV ribozyme, and the BGH termination and polyadenylation sequences, flanked at the 5 '-end by a multicloning site with the restriction sites selected before (BamHI, StuI, SwaI, and PacI) and at the 3 '-end by the restriction site SfiI. This DNA fragment could be generated by chemical synthesis or by overlapping PCR as described before (see Notes 6 and 7).

4. Digest with BamHI and SfiI the second DNA fragment (containing the multicloning site, the viral $3^{\prime}$-end followed by the 


\subsubsection{Assembly of the Full-Length cDNA Clone}

\subsection{Generation and Manipulation of BAC Clones}

\subsubsection{Isolation of BAC} Plasmids from Small-Scale Cultures
poly(A) tail, and the HDV-BGH sequences) and clone it into the plasmid pBAC-MERS-CoV 5' digested with the same restriction enzymes to generate the intermediate plasmid pBAC-MERS-CoV 5'-3' (Fig. 2).

5. After each cloning step, the integrity of the cloned DNA fragments is verified by restriction analysis and sequencing.

1. The full-length cDNA clone (pBAC-MERS-CoV ${ }^{\mathrm{FL}}$ ) is assembled by sequential cloning of overlapping DNA fragments (MERS-1 to MERS-4), covering the entire viral genome, into the intermediate plasmid pBAC-MERS-CoV $5^{\prime}-3^{\prime}$ using the restriction sites selected in the first step of the cloning strategy (Fig. 2) ( see Note 8).

2. The overlapping DNAs flanked by the appropriated restriction sites are generated either by chemical synthesis or by standard reverse transcriptase PCR (RT-PCR) (see Note 6) using specific oligonucleotides and total RNA from infected cells as template. In the case of fragment MERS-3, a silent mutation ( $\mathrm{T}$ to C) was introduced at position 20,761 to abrogate the SwaI restriction site at position 20,760 . This mutation facilitates the cloning process and can be used as a genetic marker to identify the virus recovered from the full-length cDNA clone.

3 . The genetic integrity of the cloned DNAs is verified throughout the subcloning and assembly process by extensive restriction analysis and sequencing.

One of the major advantages of using $\mathrm{BAC}$ vectors to generate infectious clones is that the manipulation of $\mathrm{BAC}$ clones is relatively easy and essentially the same as that of a conventional plasmid with slight modifications due to the huge size of the BAC clones and the presence of this plasmid in only one or two copies per cell [11]. The amplification and isolation of BAC plasmids is performed using standard procedures described for conventional plasmids but using large volumes of bacterial cultures.

Small amounts of BAC DNAs are prepared from $5 \mathrm{ml}$ cultures of BAC transformed DHIOB cells by the alkaline lysis method. Any commercial kit could be used, but we suggest the QIAprep Miniprep Kit (Qiagen) following the recommendations for purification of large low-copy plasmids.

1. Streak the bacterial stock containing the BAC plasmid onto a LB agar plate containing $12.5 \mu \mathrm{g} / \mathrm{ml}$ chloramphenicol and incubate for 16 h at $37^{\circ} \mathrm{C}$ ( see Note 9).

2. Inoculate a single colony in $5 \mathrm{ml}$ of LB medium plus $12.5 \mu \mathrm{g} / \mathrm{ml}$ chloramphenicol in a flask with a volume of at least four times the volume of the culture and incubate for $16 \mathrm{~h}$ at $37^{\circ} \mathrm{C}$ with vigorous shaking (250 rpm) (see Note 10). 
3.2.2 Isolation of Ultrapure BAC Plasmids from Large-Scale Cultures
3.2.3 Preparation of DH1OB Competent Cells for Electroporation
3. Harvest the bacterial cells in $15 \mathrm{ml}$ centrifuge tubes by centrifugation at $6,000 \times g$ for $10 \mathrm{~min}$ at $4{ }^{\circ} \mathrm{C}$ and pour off the supernatant fluid.

4. Purify the BAC plasmid following the manufacturer's instructions. Owing to the size of BAC DNAs and the need to use large culture volumes, we recommend duplicating the volume of buffers P1, P2, and N3, performing the optional wash step with buffer PB, and eluting the DNA from the QIAprep membrane using buffer EB preheated at $70{ }^{\circ} \mathrm{C}$ ( see Note 11$)$.

5. Depending of the BAC size, yields of $0.1-0.4 \mu \mathrm{g}$ can be obtained. Although the BAC DNA prepared by this method is contaminated with up to $30 \%$ of bacterial genomic DNA, it is suitable for analysis by restriction enzyme digestion or PCR.

Large-scale preparation of ultrapure BAC DNA suitable for all critical applications, including subcloning, DNA sequencing or transfection experiments, is performed by alkaline lysis with the Qiagen Large-Construct Kit, which has been specifically developed and adapted for BAC purification. This kit integrates an ATP-dependent exonuclease digestion step that enables efficient removal of bacterial genomic DNA contamination to yield ultrapure BAC DNA.

1. Inoculate a single colony from a freshly streaked plate (LB agar plate containing $12.5 \mu \mathrm{g} / \mathrm{ml}$ chloramphenicol) (see Note 9) in $5 \mathrm{ml}$ of LB medium containing $12.5 \mu \mathrm{g} / \mathrm{ml}$ chloramphenicol and incubate for $8 \mathrm{~h}$ at $37^{\circ} \mathrm{C}$ with vigorous shaking $(250 \mathrm{rpm})$.

2. Dilute $1 \mathrm{ml}$ of the culture into $500 \mathrm{ml}$ of selective LB medium (see Note 10) pre-warmed to $37^{\circ} \mathrm{C}$ and grow the cells with vigorous shaking $(250 \mathrm{rpm})$ in a 21 flask at $37^{\circ} \mathrm{C}$ for $12-16 \mathrm{~h}$, to an OD at $550 \mathrm{~nm}$ between 1.2 and 1.5. This cell density typically corresponds with the transition from a logarithmic to a stationary growth phase ( see Note 12).

3. Harvest the bacterial cells by centrifugation at $6,000 \times g$ for $15 \mathrm{~min}$ at $4{ }^{\circ} \mathrm{C}$ and purify the BAC DNA with the Qiagen Large-Construct Kit according to the manufacturer's specifications (see Note 13). Depending of the BAC size, yields of 20-35 $\mu \mathrm{g}$ of ultrapure BAC DNA can be obtained.

Owing to the large size of BAC plasmids, the cloning of DNA fragments in BACs requires the use of DH10B competent cells with transformation efficiencies higher than $1 \times 10^{8}$ transformant colonies per $\mu \mathrm{g}$ of DNA. These efficiencies are easily obtained by the electroporation method, which is more reproducible and efficient than the chemical methods. Here we described the protocol for preparing electrocompetent DH10B cells from 11 of bacterial culture. All the steps of this protocol should be carried out under sterile conditions. 
1. Inoculate a single colony of $\mathrm{DH} 10 \mathrm{~B}$ cells from a freshly streaked LB agar plate into a flask containing $10 \mathrm{ml}$ of SOB medium and incubate the culture overnight at $37^{\circ} \mathrm{C}$ with vigorous shaking $(250 \mathrm{rpm})$.

2. Dilute $1 \mathrm{ml}$ of the overnight culture into 11 of SOB medium pre-warmed at $37^{\circ} \mathrm{C}$ and grow the cells with vigorous shaking $(250 \mathrm{rpm})$ in a 21 flask at $37{ }^{\circ} \mathrm{C}$ until the $\mathrm{OD}$ at $550 \mathrm{~nm}$ reaches 0.7 (this can take $4-5$ h) (see Note 14).

3. Transfer the flask to an ice-water bath for about $20 \mathrm{~min}$. Swirl the culture occasionally to ensure that cooling occurs evenly. From this point on, it is crucial that the temperature of the bacteria not rise above $4{ }^{\circ} \mathrm{C}$.

4. Divide the bacteria culture in two ice-cold $500 \mathrm{ml}$ centrifuge bottles and harvest the cells by centrifugation at $6,000 \times g$ for $10 \mathrm{~min}$ at $4{ }^{\circ} \mathrm{C}$. Discard the supernatant and resuspend each cell pellet in $500 \mathrm{ml}$ of ice-cold $10 \%$ glycerol in sterile water.

5. Harvest the cells by centrifugation at $6,000 \times g$ for $15 \mathrm{~min}$ at $4{ }^{\circ} \mathrm{C}$. Carefully pour off the supernatant and resuspend each cell pellet in $250 \mathrm{ml}$ of ice-cold $10 \%$ glycerol (see Note 15).

6. Repeat step 5 reducing the resuspension volume to $125 \mathrm{ml}$ from each cell pellet.

7. Harvest the cells by centrifugation at $6,000 \times g$ for $15 \mathrm{~min}$ at $4^{\circ} \mathrm{C}$. Carefully pour off the supernatant (see Note 15) and remove any remaining drops of buffer using a Pasteur pipette attached to a vacuum line.

8. Resuspend the cells in a final volume of $3 \mathrm{ml}$ ice-cold $10 \%$ glycerol, avoiding the generation of bubbles. This volume has been calculated to reach an optimal cell concentration of $2-4 \times 10^{10}$ cells $/ \mathrm{ml}$.

9. Transfer $50 \mu \mathrm{l}$ of the suspension to an ice-cold electroporation cuvette $(0.2-\mathrm{cm}$ gap) and test whether arcing occurs when an electrical discharge is applied with the electroporation apparatus using the conditions described in Subheading 3.2.6, step 4. Arcing is usually manifested by the generation of a popping sound in the cuvette during the electrical pulse. If arcing occurs, wash the cell suspension once more with $100 \mathrm{ml} 10 \%$ glycerol and repeat steps 7 and $\mathbf{8}$.

10. Dispense $100 \mu \mathrm{l}$ aliquots of the final cell suspension into sterile, ice-cold $1.5 \mathrm{ml}$ microfuge tubes, freeze quickly in a dry ice-methanol bath, and transfer to a $-70{ }^{\circ} \mathrm{C}$ freezer. Electrocompetent $\mathrm{DH} 10 \mathrm{~B}$ cells could be stored at $-70{ }^{\circ} \mathrm{C}$ for up to 6 months without loss of transforming efficiency. 
3.2.4 Cloning of DNA Fragments in BACs: Preparation of BAC Vectors and DNA Inserts

\subsubsection{Ligation Reaction}

The same standard techniques used for the cloning of DNA in conventional plasmids are applied to BACs with special considerations owing to the large size of BAC plasmids.

1. Digest the BAC vector and foreign DNA with a two- to threefold excess of the desired restriction enzymes for $3 \mathrm{~h}$ using the buffers supplied with the enzymes and check a small aliquot of the digestions by agarose gel electrophoresis to ensure that the entire DNA has been cleaved. Use an amount of target DNA sufficient to yield $2 \mu \mathrm{g}$ of the BAC vector and $0.25-0.5 \mu \mathrm{g}$ of the desired DNA insert.

2. When two enzymes requiring different buffers are used to digest the DNA, carry out the digestion sequentially with both enzymes. Clean the DNA after the first digestion by extraction with phenol-chloroform and standard ethanol precipitation or by using the Qiagen QIAEX II Gel Extraction Kit following the manufacturer's instructions for purifying DNA fragments from aqueous solutions (see Note 16).

3. Purify the digested BAC vector and the DNA insert by agarose gel electrophoresis using the Qiagen QIAEX II Gel Extraction Kit following the manufacturer's instructions (see Note 16).

4. Determine the concentration of the BAC vector and the insert by UV spectrophotometry or by quantitative analysis on an agarose gel.

5. If the BAC vector was digested with only one restriction enzyme or with restriction enzymes leaving compatible or blunt ends, the digested BAC vector has to be dephosphorylated prior to its purification by agarose gel electrophoresis to suppress self-ligation of the BAC vector. We recommend cleaning the DNA before the dephosphorylation reaction as described in step 2 and using shrimp alkaline phosphatase following the manufacturer's specifications.

1. For protruding-ended DNA ligation, mix in a sterile microfuge tube $150 \mathrm{ng}$ of purified digested BAC vector, an amount of the purified insert equivalent to a molar ratio of insert to vector of $3: 1,1.5 \mu$ of $10 \times$ T4 DNA ligase buffer containing $10 \mathrm{mM}$ ATP, 3 Weiss unit of T4 DNA ligase, and water to a final volume of $15 \mu \mathrm{l}$. In separate tubes, set up two additional ligations as controls, one containing only the vector and the other containing only the insert. Incubate the reaction mixtures for $16 \mathrm{~h}$ at $16^{\circ} \mathrm{C}($ see Note 17$)$.

2 . In the case of blunt-ended DNAs, to improve the ligation efficiency use $225 \mathrm{ng}$ of vector, the corresponding amount of insert, 6 Weiss unit of T4 DNA ligase, and incubate the reaction mixtures for $20 \mathrm{~h}$ at $14^{\circ} \mathrm{C}$. 


\subsubsection{Transformation of DH10B Competent Cells by Electroporation}

3.2.7 Screening of Bacterial Colonies by $P C R$
1. Thaw the electrocompetent DHIOB cells at room temperature and transfer them to an ice bath.

2. For each transformation, pipette $50 \mu$ of electrocompetent cells into an ice-cold sterile $1.5 \mathrm{ml}$ microfuge tube and place it on ice together with the electroporation cuvettes.

3. Dilute $2.5 \mu$ of the ligation reaction (about $25 \mathrm{ng}$ of DNA) in $47.5 \mu$ of sterile water, mix with the competent cells and incubate the mixture on ice for $1 \mathrm{~min}$. For routine transformation with supercoiled BACs, add 0.1 ng of DNA in a final volume of $2 \mu \mathrm{l}$. Include all the appropriate positive and negative controls.

4. Set the electroporation machine to deliver an electrical pulse of $25 \mu \mathrm{F}$ capacitance, $2.5 \mathrm{kV}$, and $100 \Omega$ resistance (see Note 18).

5. Add the DNA-cells mixture into the cold electroporation cuvette avoiding bubbles formation and ensuring that the DNA-cells mixture sits at the bottom of the cuvette. Dry the outside of the cuvette with filter paper and place the cuvette in the electroporation device.

6. Deliver an electrical pulse at the settings indicated above. A time constant of $4-5 \mathrm{~ms}$ should be registered on the machine (see Note 19).

7. Immediately after the electrical pulse, remove the cuvette and add $1 \mathrm{ml}$ of SOC medium pre-warmed at room temperature.

8. Transfer the cells to a $17 \times 100-\mathrm{mm}$ polypropylene tube and incubate the electroporated cells for $50 \mathrm{~min}$ at $37^{\circ} \mathrm{C}$ with gentle shaking $(250 \mathrm{rpm})$.

9. Plate different volumes of the electroporated cells $(2.5,20$, and $200 \mu \mathrm{l})$ onto LB agar plates containing $12.5 \mu \mathrm{g} / \mathrm{ml}$ chloramphenicol and incubate them at $37^{\circ} \mathrm{C}$ for $16-24 \mathrm{~h}$ ( see Note 20).

The recombinant colonies containing the insert in the correct orientation are identified by direct PCR analysis using specific oligonucleotides and conventional Taq DNA polymerase (see Note 21).

1. For each bacterial colony prepare a PCR tube with $25 \mu \mathrm{l}$ of sterile water.

2. Using sterile yellow tips, pick the bacterial colonies, make small streaks $(2-3 \mathrm{~mm})$ on a fresh LB agar plate containing $12.5 \mu \mathrm{g} / \mathrm{ml}$ chloramphenicol to make a replica, and transfer the tips to the PCR tubes containing the water (see Note 22). In separate tubes, set up positive and negative controls. Leave the tips inside the PCR tubes for $5 \mathrm{~min}$ at room temperature.

3 . During this incubation time, prepare a $2 \times$ master mix containing $2 \times$ PCR buffer, $3 \mathrm{mM} \mathrm{MgCl}_{2}$ (it has to be added only in the case that the PCR buffer does not contain $\left.\mathrm{MgCl}_{2}\right), 0.4 \mathrm{mM}$ dNTPs, $2 \mu \mathrm{M}$ of each primer, and $2.5 \mathrm{U}$ of Taq DNA 
3.2.8 Storage of Bacterial Cultures

3.2.9 Modification of BAC Clones

\subsection{Rescue of Recombinant Viruses}

polymerase per each $25 \mu \mathrm{l}$ of master mix. Prepare the appropriate amount of $2 \times$ master mix taking into consideration that the analysis of each colony requires $25 \mu \mathrm{l}$ of this master mix.

4. Remove the yellow tip and add $25 \mu \mathrm{l}$ of $2 \times$ master mix to each PCR tube.

5. Transfer the PCR tubes to the thermocycler and run a standard PCR, including an initial denaturation step at $95^{\circ} \mathrm{C}$ for 5 min to liberate and denature the DNA templates and to inactivate proteases and nucleases.

6. Analyze the PCR products by electrophoresis through an agarose gel.

7. Pick the positive colonies from the replica plate and isolate the BAC DNA as described in Subheadings 3.2.1 and 3.2.2 for further analysis.

1. Mix $0.5 \mathrm{ml}$ of LB freezing buffer with $0.5 \mathrm{ml}$ of an overnight bacterial culture in a cryotube with a screw cap.

2. Vortex the culture to ensure that the glycerol is evenly dispersed, freeze in ethanol-dry ice, and transfer to $-70{ }^{\circ} \mathrm{C}$ for long-term storage.

3. Alternatively, a bacterial colony can be stored directly from the agar plate without being grown in liquid media. Using a sterile yellow tip, scrape the bacteria from the agar plate and resuspend the cells into $200 \mu \mathrm{l}$ of LB medium in a cryotube with a screw cap. Add an equal volume of LB freezing buffer, vortex the mixture, and freeze the bacteria as described in step 2 (see Note 23).

The modification of BAC clones is relatively easy and it is performed using the same techniques as for conventional plasmids with the modifications described in this chapter. We recommend introducing the desired modifications into intermediate BAC plasmids containing the different viral cDNA fragments used during the assembly of the full-length cDNA clone, and then inserting the modified cDNA into the infectious clone by restriction fragment exchange. Besides standard protocols, the BAC clones can be easily and efficiently modified in $E$. coli by homologous recombination using a two-step procedure that combines the Red recombination system and counterselection with the homing endonuclease I-SceI [17-20] ( see Note 24).

Infectious virus is recovered by transfection of susceptible cells with the full-length cDNA clone using the cationic lipid Lipofectamine 2000 as transfection reagent (see Note 25). When the transfection efficiency of the susceptible cells is very low, we recommend first transfecting BHK-2l cells and then plating these 
cells over a monolayer of susceptible cells to allow virus propagation. BHK-21 cells are selected because they present good transfection efficiencies and support the replication of most known CoVs after transfection of the viral genome. The following proto$\mathrm{col}$ is indicated for a $35-\mathrm{mm}$-diameter dish and can be upscaled or downscaled if desired ( see Note 26).

1. One day before transfection, plate $4 \times 10^{5} \mathrm{BHK}-21$ cells in $2 \mathrm{ml}$ of growth medium without antibiotics to obtain 90-95\% confluent cell monolayers by the time of transfection ( see Note 27). Also plate susceptible cells (Huh-7 cells in the case of MERS-CoV) at the required confluence for the amplification of the recombinant virus after transfection.

2. Before transfection, equilibrate the Opti-MEM I Reduced Serum Medium at room temperature and put the DNA (see Note 28) and the Lipofectamine 2000 reagent on ice. For each transfection sample, prepare transfection mixtures in sterile microfuge tubes as follows:

(a) Dilute $5 \mu \mathrm{g}$ of the BAC clone in $250 \mu \mathrm{l}$ of Opti-MEM medium. Mix carefully, avoiding prolonged vortexing or pipetting to prevent plasmid shearing.

(b) Mix Lipofectamine 2000 gently before use. Dilute $12 \mu \mathrm{l}$ of Lipofectamine 2000 in $250 \mu$ of Opti-MEM medium (see Note 29), mix by vortexing, and incubate the diluted Lipofectamine 2000 at room temperature for $5 \mathrm{~min}$.

(c) Combine the diluted DNA with diluted Lipofectamine 2000, mix carefully, and incubate for $20 \mathrm{~min}$ at room temperature.

3. During this incubation period, wash the BHK-2l cells once with growth medium without antibiotics and leave the cells in $1 \mathrm{ml}$ of the same medium per dish.

4. Add the $500 \mu \mathrm{l}$ of the DNA-Lipofectamine 2000 mixture onto the washed cells and mix by rocking the plate back and forth. Incubate the cells at $37^{\circ} \mathrm{C}$ for $6 \mathrm{~h}$ ( see Note 30).

5 . Remove the transfection medium, wash the cells with trypsinEDTA solution, and detach the cells using $300 \mu \mathrm{l}$ of trypsinEDTA solution.

6. Add $700 \mu \mathrm{l}$ of growth media to collect the cells and reseed them over a confluent monolayer of susceptible cells containing $1 \mathrm{ml}$ of normal growth medium.

7. Incubate at $37^{\circ} \mathrm{C}$ until a clear cytopathic effect was observed.

8. Analyze the presence of virus in the supernatant by titration.

9. Clone the virus by three rounds of plaque purification and analyze the genotypic and phenotypic properties of the recovered virus. 


\section{Notes}

1. E. coli $\mathrm{DH} 10 \mathrm{~B}$ strain is a recombination-defective strain used for the propagation of BACs to avoid unwanted rearrangements.

2. SOB medium should be $\mathrm{Mg}^{2+}$-free to avoid arcing during the electroporation step.

3. The Huh-7 cell line has never been deposited at ATCC but it can be purchased from the Japanese Collection of Research Bioresources (JCRB) Cell Bank.

4. In case that a restriction site present in the BAC plasmid was selected, it must be removed in the plasmid by the introduction of silent mutations.

5. The silent mutations introduced in the viral genome to generate new restriction sites or to abrogate preexisting ones can be used as genetic markers to identify the virus recovered from the infectious clone.

6. To reduce the number of undesired mutations, perform all PCR reactions with a high-fidelity polymerase, according to the manufacturer's instructions.

7. The CMV promoter and the BGH termination and polyadenylation sequences can be amplified from pcDNA3.1. Alternatively, these sequences together with the HDV ribozyme could be amplified from plasmid pBAC-TGEV $5^{\prime}-3^{\prime}$ that is available from the authors upon request.

8. In general, the cloning of $\mathrm{CoV}$ full-length cDNAs in BACs allows the stable propagation of the infectious clone in E. coli $\mathrm{DH} 10 \mathrm{~B}$ cells. If a residual toxicity, characterized by a small colony phenotype and a delay in the bacterial growth, is observed during the assembly of the infectious clone, we recommend inserting the DNA fragment responsible for this toxicity in the last cloning step to minimize the toxicity problem.

9. Cultures of BAC transformed bacteria should be grown from a single colony isolated from a freshly streaked selective plate. Subculturing directly from glycerol stocks or plates that have been stored for a long time may lead to loss of the construct.

10. $\mathrm{LB}$ broth is the recommended culture medium, since richer broths such as TB (Terrific Broth) lead to extremely high cell densities, which can overload the purification system, resulting in lower yield and less purity of the BAC DNA.

11. When other kits are used instead of the Qiagen QIAprep Miniprep Kit, equivalent modifications have to be included to optimize the recovery of BAC DNA.

12. To avoid DNA degradation and unwanted rearrangements owing to culture overaging, it is important to prevent growing the culture up to the late stationary growth phase. 
13. The use of a swinging bucket rotor is recommended for the last isopropanol precipitation step to facilitate the further resuspension of the BAC DNA. After washing with $70 \%$ ethanol, air-dry the pellet for only $5 \mathrm{~min}$. Never use vacuum, as overdrying the pellet will make the BAC DNA difficult to dissolve. Carefully remove any additional liquid drop, add $250 \mu \mathrm{l}$ of $10 \mathrm{mM}$ Tris- $\mathrm{HCl}$ ( $\mathrm{pH}$ 8.5) (DNA dissolves better under slightly alkaline conditions) and resuspend the DNA overnight at $4{ }^{\circ} \mathrm{C}$. To prevent plasmid shearing, avoid vortexing or pipetting to promote resuspension of the BAC DNA. Transfer the DNA to a clean $1.5 \mathrm{ml}$ microfuge tube, remove any possible resin traces by centrifugation for $1 \mathrm{~min}$ in a tabletop microfuge, and keep the supernatant in a clean tube at $4{ }^{\circ} \mathrm{C}$. If the purified BAC DNA is not going to be used for a long period of time we recommend storage at $-20^{\circ} \mathrm{C}$. Avoid repeated freezethaw cycles to prevent plasmid shearing.

14. For efficient cell transformation, bacterial culture OD at $550 \mathrm{~nm}$ should not exceed 0.8 . To ensure that the culture does not grow to a higher density, OD measurement every $20 \mathrm{~min}$ after $3 \mathrm{~h}$ of growth is highly recommended.

15. Take care when decanting the supernatant as the bacterial pellets lose adherence in $10 \%$ glycerol.

16. The Qiagen QIAEX II resin can be used to efficiently purify DNA fragments from $40 \mathrm{bp}$ to $50 \mathrm{~kb}$ from aqueous solutions and from standard or low-melt agarose gels in TAE or TBE buffers. Other commercial kits are available, but check whether they have been optimized for purification of DNA fragments larger than $10 \mathrm{~kb}$, as most BAC constructs used during the assembly of the infectious clone are larger than $10 \mathrm{~kb}$.

17. The large size of the BAC vectors reduces the ligation efficiency. To increase this efficiency, it is essential to use larger amounts of vector, insert, and T4 DNA ligase than when using conventional plasmids.

18. Most electroporation machines contain programs with defined parameters for transforming specific cell types. In this case, choose the program containing the conditions closest to those described in this protocol.

19. The presence of salt increases the conductivity of the solution and could cause arcing during the electrical pulse, drastically reducing the transformation efficiency. If arcing occurs, use a smaller amount of the ligation reaction in the electroporation or remove salt from the DNA using any commercial kit or by extraction with phenol-chloroform followed by precipitation with ethanol and $2 \mathrm{M}$ ammonium acetate.

20. Plating volumes higher than $200 \mu \mathrm{l}$ of electroporated cells on a single plate may inhibit the growth of transformants owing to the large number of dead cells resulting from electroporation. 
If only small numbers of transformant colonies are expected, it is recommended to spread $200 \mu \mathrm{l}$-aliquots of the electroporated cells on different plates.

21. A mix of small and large colonies indicates that the cloned DNA fragment presents some toxicity when amplified in $E$. coli. Choose the small colonies, which may contain the correct insert, and always grow the bacteria containing this recombinant BAC plasmid at $30^{\circ} \mathrm{C}$ to minimize the toxicity problem. In this case, we strongly recommend inserting this toxic DNA fragment into the infectious clone in the last cloning step, in order to reduce the manipulation and minimize the possibility of introducing unwanted mutations. Infectious $\mathrm{BAC} \mathrm{cDNA}$ clones presenting a residual toxicity should be grown at $30^{\circ} \mathrm{C}$.

22. It is important to avoid overloading the reaction by adding too much bacteria, which may alter the ionic balance of the reaction and inhibit the amplification by the Taq polymerase.

23. We recommend to use this storage method for BAC clones that present a residual toxicity and are not fully stable when amplified in E. coli.

24. The Red recombination system combined with counterselection with I-SceI endonuclease results in an accurate and highly efficient method to introduce insertions, deletions, or point mutations in BAC clones without retention of unwanted foreign sequences.

25. The transfection of BACs containing large inserts into mammalian cells has been optimized in our laboratory and the best transfection efficiencies were provided using Lipofectamine 2000 as transfection reagent.

26. All work involving MERS-CoV has to be performed in a Biosafety Level 3 (BSL3) laboratory, following the guidelines of the European Commission and the National Institutes of Health (NIH) of the USA.

27. Do not add antibiotics to media during transfection as this may decrease transfection activity. A healthy cell culture is critical for an efficient transfection. The use of low passagenumber cells is recommended.

28. Use a BAC DNA isolated with the Qiagen Large-Construct Kit since a DNA preparation of high purity is required in the transfection step.

29. Opti-MEM I Reduced Serum Medium is recommended for dilution of the cationic lipid Lipofectamine 2000 reagent prior to complexing with DNA, although other media without serum may also be used. However, owing that some serumfree media formulations can inhibit cationic lipid-mediated transfection, test any new serum-free medium for compatibility 
with the transfection reagent prior to use. Some media formulations that have been found to inhibit cationic lipid-mediated transfection are CD 293 Medium, 293 SFM II, and VP-SFM.

30. If susceptible cells are directly transfected, incubate them at $37^{\circ} \mathrm{C}$ until the cytopathic effect is observed and proceed to clone and characterize the recovered virus. In this case, optimization of the transfection of the desired cells with the BAC clone using Lipofectamine 2000 should be required. For transfection optimization, use a similar size plasmid expressing GFP. This plasmid is available from the authors upon request.

\section{Acknowledgements}

This work was supported by grants from the Ministry of Science and Innovation of Spain (MCINN) (BIO2010-16705), the European Community's Seventh Framework Programme (FP7/2007-2013) under the project "EMPERIE" (HEALTH-F3-2009-223498), and the National Institute of Health (NIH) of the USA (2P01AI060699-06Al). S. M. received a predoctoral fellowship from the National Institute of Health (ISCIII) of Spain.

\section{References}

1. Masters PS (2006) The molecular biology of coronaviruses. Adv Virus Res 66:193-292

2. Lai MMC, Perlman S, Anderson L (2007) Coronaviridae. In: Knipe DM, Howley PM, Griffin DE, Lamb RA, Martin MA, Roizman B, Straus SE (eds) Fields virology, vol 1, 5th edn. Lippincott Williams and Wilkins, Philadelphia, pp 1305-1335

3. Stadler K, Masignani V, Eickmann $M$ et al (2003) SARS-beginning to understand a new virus. Nat Rev Microbiol 1:209-218

4. Zaki AM, van Boheemen S, Bestebroer TM et al (2012) Isolation of a novel coronavirus from a man with pneumonia in Saudi Arabia. N Engl J Med 367:1814-1820

5. Almazán F, González JM, Pénzes Z et al (2000) Engineering the largest RNA virus genome as an infectious bacterial artificial chromosome. Proc Natl Acad Sci U S A 97:5516-5521

6. Yount B, Curtis KM, Baric RS (2000) Strategy for systematic assembly of large RNA and DNA genomes: transmissible gastroenteritis virus model. J Virol 74:10600-10611

7. Thiel V, Herold J, Schelle B et al (2001) Infectious RNA transcribed in vitro from a
cDNA copy of the human coronavirus genome cloned in vaccinia virus. J Gen Virol 82:1273-1281

8. Casais R, Thiel V, Siddell SG et al (2001) Reverse genetics system for the avian coronavirus infectious bronchitis virus. J Virol 75: 12359-12369

9. van Boheemen S, de Graaf M, Lauber C et al (2012) Genomic characterization of a newly discovered coronavirus associated with acute respiratory distress syndrome in humans. $\mathrm{mBio}$ 3, e00473-12

10. Wang K, Boysen C, Shizuya H et al (1997) Complete nucleotide sequence of two generations of a bacterial artificial chromosome cloning vector. Biotechniques 23:992-994

11. Shizuya H, Birren B, Kim UJ et al (1992) Cloning and stable maintenance of 300-kilobase-pair fragments of human DNA in Escherichia coli using an F-factor-based vector. Proc Natl Acad Sci U S A 89: 8794-8797

12. Dubensky TW, Driver DA, Polo JM et al (1996) Sindbis virus DNA-based expression vectors: utility for in vitro and in vivo gene transfer. J Virol 70:508-519 
13. Bálint A, Farsang A, Zádori Z et al (2012) Molecular characterization of feline infectious peritonitis virus strain DF-2 and studies of the role of ORF3abc in viral cell tropism. J Virol 86:6258-6267

14. St-Jean JR, Desforges M, Almazán F et al (2006) Recovery of a neurovirulent human coronavirus OC43 from an infectious cDNA clone. J Virol 80:3670-3674

15. Almazán F, DeDiego ML, Galán C et al (2006) Construction of a severe acute respiratory syndrome coronavirus infectious cDNA clone and a replicon to study coronavirus RNA synthesis. J Virol 80:10900-10906

16. Almazán F, DeDiego ML, Sola I et al (2013) Engineering a replication-competent, propagation-defective Middle East respiratory syndrome coronavirus as a vaccine candidate. mBio 4, e00650-00613
17. Zhang Y, Buchholz F, Muyrers JPP et al (1998) A new logic for DNA engineering using recombination in Escherichia coli. Nat Genet 20:123-128

18. Lee EC, Yu D, Martinez de Velasco J et al (2001) A highly efficient Escherichia colibased chromosome engineering system adapted for recombinogenic targeting and subcloning of BAC DNA. Genomics 73:56-65

19. Jamsai D, Orford M, Nefedov M et al (2003) Targeted modification of a human beta-globin locus BAC clone using GET recombination and an I-SceI counterselection cassette. Genomics 82:68-77

20. Tischer BK, von Einem J, Kaufer B et al (2006) Two-step red-mediated recombination for versatile high-efficiency markerless DNA manipulation in Escherichia coli. Biotechniques 40:191-197 